\title{
QUALIDADE MICROBIOLÓGICA DO LEITE CAPRINO EM PROPRIEDADES RURAIS DA REGIÃO DE MACAÍBA/RN
}

\section{Microbiological quality of goat milk on rural properties in the region of Macaíba/RN}

\author{
Joyce Bruna Paiva Silva ${ }^{1 *}$, Cláudia Souza Macêdo ${ }^{l}$, \\ Sâmara Monique da Silva Oliveira ${ }^{l}$, Adriano Henrique do Nascimento Rangel ${ }^{l}$, \\ Lisandra Mürmann ${ }^{I}$
}

\begin{abstract}
RESUMO
O leite de cabra é um excelente alimento que pode garantir efeitos benéficos à saúde humana, porém suas características são facilmente alteradas pela ação de microrganismos e pela manipulação. O presente estudo teve como objetivo avaliar a qualidade microbiológica do leite caprino em 11 propriedades rurais da região de Macaíba/RN. As amostras de leite e dos swab das mãos dos ordenhadores, utensílios e tetos caprinos foram coletadas e transportadas em caixa térmica $\left(10^{\circ} \mathrm{C}-12{ }^{\circ} \mathrm{C}\right)$ para o Laboratório de Engenharia de Alimentos da UFRN. Os microrganismos pesquisados foram as bactérias aeróbias mesófilas, psicrotróficos, estafilococos coagulase positiva e negativa, coliformes a $35^{\circ} \mathrm{C}$ e a $45^{\circ} \mathrm{C}$. Com relação às mãos dos ordenhadores, $56 \%$ apresentaram contaminação por bactérias aeróbias mesófilas. Nos utensílios analisados foram encontrados, em $18,2 \%$, coliformes a $45^{\circ} \mathrm{C}$ e estafilococos coagulase positiva, bem como estafilococos coagulase negativa $(63,6 \%)$ e coliformes a $35{ }^{\circ} \mathrm{C}$ em $27,3 \%$ das amostras. Para o leite caprino cru resfriado, $10 \%$ das amostras apresentaram contaminação por psicrotróficos e $17 \%$ apresentaram coliformes a $45^{\circ} \mathrm{C}$. Com relação aos tetos caprinos, $52 \%$ das amostras apresentaram contagem de bactérias aeróbias mesófilas acima de $10^{3} \mathrm{UFC} /$ teto, $61 \%$ apresentaram estafilococos coagulase negativa e $10 \%$ estafilococos coagulase positiva, sendo este um dos principais agentes causadores da mastite. Assim, estes valores traduzem que medidas higiênicas precisam ser adotadas adequadamente na coleta
\end{abstract}

1 Universidade Federal do Rio Grande do Norte (UFRN), Campus Universitário Lagoa Nova, caixa postal 1524, 59078-970, Natal, RN, Brasil. E-mail: joycebrunapaiva@hotmail.com

* Autor para correspondência.

Recebido / Received: 29/03/2017

Aprovado / Approved: 28/08/2017 
do leite caprino cru, necessitando de orientações que capacitem os produtores para obtenção de leite de maior qualidade.

Palavras-chave: higiene; mãos; tetos; utensílios; ordenhadores.

\begin{abstract}
Goat's milk is an excellent food that can guarantee beneficial effects to human health, but its characteristics are easily altered by the action of microorganisms and by manipulation. The present study aimed to evaluate the microbiological quality of goat milk in 11 farms in the region of Macaíba/RN. Samples of milk and swabs from the hands of milkers, utensils and goat teats were collected and transported in a thermal box $\left(10^{\circ} \mathrm{C}-12^{\circ} \mathrm{C}\right)$ to the Laboratory of Food Engineering of UFRN. The microorganisms studied were the aerobic mesophilic bacteria, psychrotrophic, coagulase positive and negative staphylococci, coliforms at $35^{\circ} \mathrm{C}$ and $45{ }^{\circ} \mathrm{C}$. Regarding the hands of milkers, $56 \%$ presented contamination by aerobic mesophilic bacteria. In the analyzed utensils were found, in $18.2 \%$, coliforms at $45^{\circ} \mathrm{C}$ and coagulase positive staphylococci, as well as coagulase negative staphylococci $(63.6 \%)$ and coliforms at $35{ }^{\circ} \mathrm{C}$ in $27.3 \%$ of the samples. For cold raw goat milk, $10 \%$ of the samples presented contamination with psychrotrophic and $17 \%$ with coliforms at $45{ }^{\circ} \mathrm{C}$. Regarding goat teats, $52 \%$ of the samples had aerobic mesophilic bacteria counts above $10^{3} \mathrm{CFU} /$ ceiling, $61 \%$ presented coagulase negative staphylococci and $10 \%$ coagulase positive staphylococci, this one of the main agents causing mastitis. Thus, these values indicate that hygienic procedures need to be adopted appropriately in the milking of raw goat milk, requiring guidelines that enable producers to obtain higher quality milk.
\end{abstract}

Keywords: hygiene; hands; teats; utensils; milkers.

\section{INTRODUÇ̃̃̃O}

A caprinocultura é uma atividade importante no agronegócio brasileiro. O Brasil possui um rebanho de mais de oito milhões de cabeças, sendo que o Nordeste destaca-se das demais regiões do Brasil e o Rio Grande do Norte ocupa a sexta posição no ranking do rebanho caprino, com um total de 397.093 cabeças (IBGE, 2013). Conforme Cardoso et al. (2010), os produtores vem superando o desafio de ocupar e manter novos mercados para o leite de cabra e seus derivados.

A procura e o consumo do leite caprino têm aumentado em razão da cabra ser um animal capaz de se adaptar a condições adversas, melhorando o nível nutricional da dieta de famílias de baixa renda, da maior procura por produtos diferenciados e também por ser uma alternativa alimentar para pessoas sensíveis ao leite de vaca, além de ser uma ótima fonte de cálcio e proteína de alto valor biológico (SILVA et al., 2011). O leite de cabra é similar ao leite de vaca em sua composição básica, no entanto, apresenta melhor digestibilidade e maior capacidade tamponante. Isso ocorre porque as partículas gordurosas no leite de cabra são menores e contém uma proporção maior de ácidos graxos (AG) de cadeia curta e média, contribuindo para uma digestão mais rápida (AMARAL et al. 2011).

Devido à riqueza nutricional do leite, este se torna um meio ideal para o crescimento 
de diferentes microrganismos, o que pode ser considerado preocupante, pois, conforme Castro et al. (2014), a qualidade do leite cru produzido no Brasil ainda necessita de uma série de adequações, uma vez que, o leite cru refrigerado deve apresentar qualidade microbiológica satisfatória. Para evitar contaminações microbianas, a Instrução Normativa $n^{\circ} 37$ do MAPA (BRASIL, 2000) determina uma série de parâmetros para todas as etapas que envolvem a obtenção do leite caprino, bem como determina os critérios microbiológicos e de tolerância que devem ser obedecidos.

Desta forma, observa-se que, se houver falta de cuidados higiênicos na cadeia produtiva ocorrerá a obtenção de leite com alta contagem microbiana, de qualidade duvidosa e fora dos padrões exigidos pela legislação, o que aumenta a probabilidade de riscos à saúde humana.

Assim, esse trabalho teve como objetivo realizar uma avaliação da qualidade microbiológica em propriedades rurais caprinas na região de Macaíba no Rio Grande do Norte, para detectar possíveis problemas e pontos de contaminação que afetam a qualidade do produto final.

\section{MATERIAL E MÉTODOS}

Foram realizadas coletas em 11 propriedades rurais localizadas na região de Macaíba-RN, com 3 repetições. As amostras de leite foram retiradas de latões armazenados no freezer, homogeneizadas por meio de agitação mecânica, coletadas em frascos esterilizados e transportadas em caixa térmica $\left(10^{\circ} \mathrm{C}-12{ }^{\circ} \mathrm{C}\right)$ para o Laboratório de Engenharia de Alimentos da UFRN, no tempo máximo de 2 horas.

As 11 amostras das mãos dos ordenhadores, 22 amostras de utensílios (11 baldes e 11 peneiras) e 33 amostras de tetos caprinos, sendo três animais de cada propriedade, foram obtidas pela técnica de swab, acondicionadas em tubos com $10 \mathrm{~mL}$ de água pepto- nada $0,1 \%$ e transportadas conforme descrito anteriormente.

Todas amostras coletadas passaram por diluições sucessivas $\left(10^{-1}, 10^{-2}\right.$ e $\left.10^{-3}\right)$ em água peptonada $0,1 \% \mathrm{e}$, em seguida, inoculadas em meios específicos e posteriormente incubadas, de acordo com os Métodos Analíticos Oficiais para Análises Microbiológicas para controle de produtos de origem animal (BRASIL, 2003).

Para as análises de coliformes totais e termotolerantes foi utilizada a técnica presuntiva do número mais provável (NMP) usando o caldo Lauril Sulfato Triptose (LST). Após incubação, os tubos positivos foram transferidos para o Caldo Verde Brilhante Bile 2\% (VB) para confirmação de coliformes totais. Em seguida, alíquotas dos tubos positivos do caldo VB foram transferidas para o caldo E. coli (EC) para verificar presença de coliformes termotolerantes. Amostras dos tubos positivos de EC foram semeadas em Ágar Levine Eosina Azul de Metileno (L-EMB), no qual as colônias com centro preto e brilho verde metálico sugerem a possível presença de E. coli.

A presença de bactérias aeróbias mesófilas e psicrotróficas foi verificada pela técnica de plaqueamento em profundidade (pour plate) e em superfície, respectivamente, em Ágar Padrão para Contagem (PCA), utilizando-se três diluições. As placas foram incubadas em estufa bacteriológica a $35^{\circ} \mathrm{C}$ para determinação de mesófilos aeróbios e a $7{ }^{\circ} \mathrm{C}$ por 10 dias para determinação de bactérias psicrotróficas.

$\mathrm{Na}$ pesquisa de estafilococos coagulase positiva e negativa foi realizada a técnica de espalhamento (spread plate) sendo as diluições semeadas em placas de Ágar BairdParker (BP) suplementado com solução de gema de ovo e telurito de potássio $(0,01 \%)$. Após o período de incubação foram realizadas as contagens das placas e selecionadas as colônias típicas para a confirmação com o teste de coagulase com Plasma-EDTA. 


\section{RESULTADOS E DISCUSSÃO}

Os resultados obtidos a partir da análise microbiológica das mãos dos ordenhadores demonstraram $56 \%$ de contaminação por bactérias aeróbias mesófilas. Também foi observada, conforme Figura 1, a presença de coliformes a $35{ }^{\circ} \mathrm{C}$, coliformes a $45^{\circ} \mathrm{C}$ e estafilococos coagulase negativa, não sendo encontrada a presença de E. coli e estafilococos coagulase positiva.

A ocorrência destes microrganismos nas mãos dos ordenhadores é preocupante, pois inferem deficiência de higienização das mãos, podendo ser transferidos ao leite. Os resultados encontrados são ratificados pelos observados por Belmont (2013), também na região de Macaíba/RN, que constatou que $67 \%$ dos ordenhadores não higienizavam as mãos antes da ordenha, procedimento este indispensável, pois, conforme Abreu et al. (2011), as mãos podem constituir fonte potencial de patógenos.
Em relação aos microrganismos mesófilos encontrados nos utensílios analisados, conforme descrito por Kochanski et al. (2009) e recomendado pela Organização Mundial de Saúde (OMS), no Brasil, contagem em placas $\leq$ $5,0 \times 10^{1} \mathrm{UFC} / \mathrm{cm}^{2}$ de superfície é considerada como satisfatória, visto que, a recomendação americana da APHA (2,0 UFC/ $\left.\mathrm{cm}^{2}\right)$ é considerada rígida para as condições brasileiras. Desta forma, das 22 amostras, 91\% estavam em desacordo e $9 \%$ atendiam ao limite sugerido pelos autores. Conforme Silva et al. (2010), populações altas de mesófilos indicam deficiências na sanitização ou falhas no controle do processo.

Conforme Figura 2, os resultados das contagens obtidas nos utensílios avaliados também apontaram a presença de estafilococos coagulase positiva, estafilococos coagulase negativa, coliformes a $35^{\circ} \mathrm{C}$ e coliformes a $45^{\circ} \mathrm{C}$, podendo ocorrer contaminação cruzada dos mesmos para o leite, demonstrando a necessidade de higienização adequada

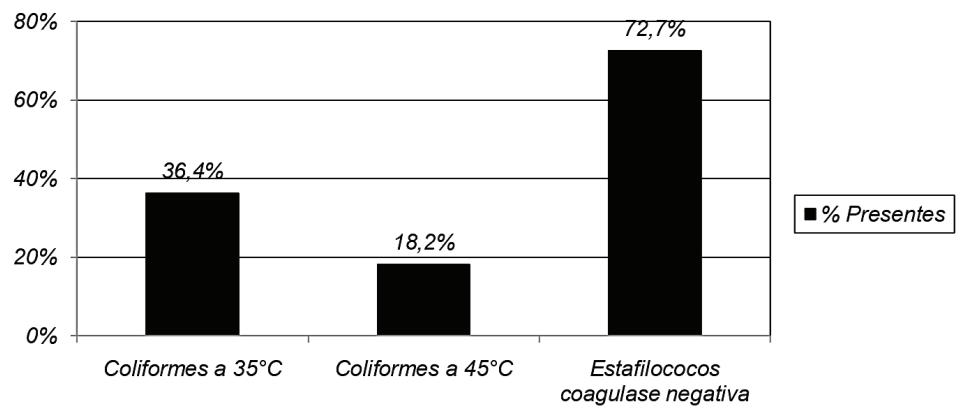

Figura 1 - Percentagem de microrganismos presentes nas mãos dos ordenhadores

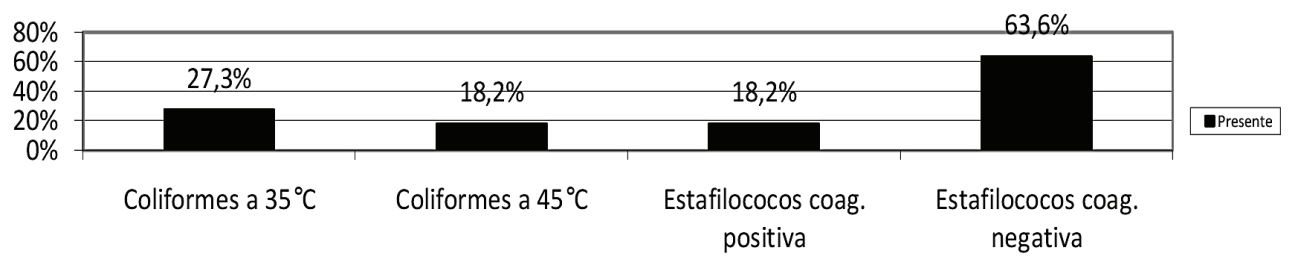

Figura 2 - Percentual de microrganismos presentes nos utensílios (balde e peneira) 
desses utensílios. A percentagem significativa de estafilococos coagulase negativa também pode ser considerada preocupante visto que, conforme Andrade et al. (2011), a ocorrência de Staphylococcus enterotoxigênicos, tanto coagulase positiva quanto negativa, em alimentos, representa um risco potencial para a saúde pública. Segundo Matsubara et al. (2011), no agreste de Pernambuco, após o início do uso das boas práticas de ordenha, os latões e baldes apresentaram reduções de $80 \%$ a $99,9 \%$ na contagem dos diversos microrganismos pesquisados.

Os resultados das amostras dos tetos dos animais demonstraram que os mesmos podem constituir importante fonte de contaminação. Das 33 amostras de tetos analisados, $52 \%$ apontaram presença das bactérias aeróbias mesófilas acima de $10^{3} \mathrm{UFC} /$ teto. Porém, este resultado pode ser modificado se o produtor aderir à prática de pré-dipping que, segundo Matsubara et al. (2011), pode determinar uma redução de até $91,3 \%$ na contagem bacteriana total do leite. Belmont (2013), pesquisando as mesmas propriedades deste trabalho, diagnosticou que o pré-dipping não era realizado em $86 \%$ das propriedades.

De acordo com a Figura 3, os microrganismos do grupo estafilococos coagulase positiva e negativa estavam presentes em 10\% e $61 \%$ dos tetos analisados, respectivamente. Esses resultados são considerados relevantes, pois Cavalcante et al. (2013) afirmaram que o estafilococos é o agente etiológico mais encontrado em mastites nas propriedades de criação de caprinos localizadas próximas a Salvador, Bahia.

Em relação aos coliformes a $35{ }^{\circ} \mathrm{C}$ e $45^{\circ} \mathrm{C}$, os mesmos ocorreram em $19 \%$ e $13 \%$ nas amostras dos tetos, respectivamente, o que pode estar relacionado ao manejo inadequado e instalações sem higiene e com fezes que podem contaminar os tetos dos animais. Belmont (2013) constatou que 15\% dos proprietários de caprinos leiteiros na região de Macaíba/RN não higienizavam os tetos antes da ordenha.

Nas análises do leite caprino cru, microrganismos do grupo coliformes a $35{ }^{\circ} \mathrm{C}$ foram encontrados em 33\% das amostras e coliformes a $45^{\circ} \mathrm{C}$ em $17 \%$ (Figura 4). Nos valores encontrados por Montes et al. (2016), para o leite caprino produzido na Paraíba, os resultados para coliformes totais variaram entre zero e $2,0 \times 10^{7} \mathrm{UFC} / \mathrm{mL}$. Conforme Salvador et al. (2012), a contaminação do leite pode se iniciar durante a ordenha pelos microrganismos presentes no teto, e depois do meio ambiente, pela ordenha realizada de forma manual ou mecânica por meio dos equipamentos e utensílios utilizados sem a higienização correta, também durante transporte, armazenamento e distribuição.

Em relação à presença de estafilococos coagulase positiva, encontrado em $7 \%$ do leite estudado, embora não tenha sido estabelecido um padrão microbiológico para este microrganismo no leite, os valores

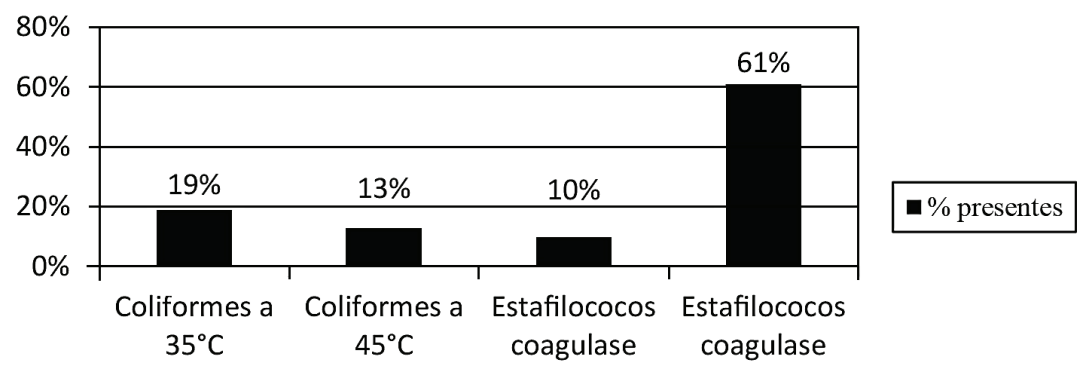

Figura 3 - Microrganismos presentes nos tetos dos caprinos 
identificados são preocupantes, pois conforme Santana et al. (2010), os estafilococos são considerados patógenos de importância dentro das Doenças Veiculadas por Alimentos (DVA), além disso, se multiplicam com facilidade em vários alimentos e produzem enterotoxinas termorresistentes.

Os resultados microbiológicos do leite caprino cru apontaram a presença de $10 \%$ das amostras com presença de bactérias psicrotróficas, sendo um fato preocupante, pois segundo Zeni et al. (2013) a contaminação do leite por microrganismos psicrotróficos produz perdas econômicas e problemas tecnológicos para a indústria, uma vez que, as enzimas proteolíticas e lipolíticas produzidas por esse grupo de microrganismos estão relacionadas à perda de qualidade e à redução de vida de prateleira do leite UHT e de outros lácteos.
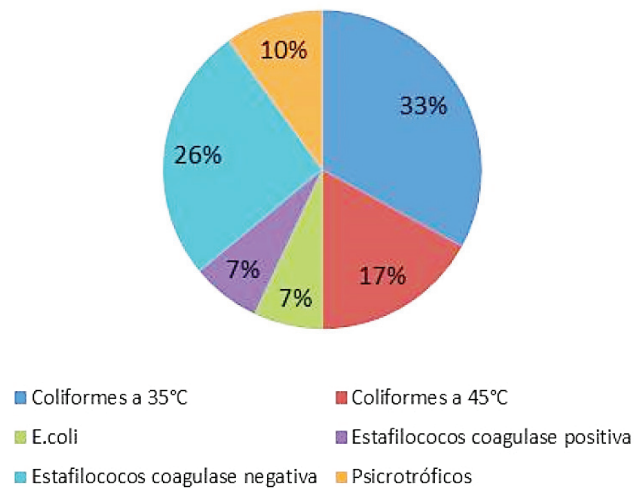

Figura 4 - Percentual de microrganismos presentes no leite de cabra cru resfriado

A qualidade microbiológica do leite cru depende basicamente das condições higinico-sanitárias adotadas no sistema de produção (SOUZA, 2011). Conforme Ribeiro Jr. et al. (2014), um expressivo número de propriedades que implantaram as boas práticas de ordenha, passou a produzir leite cru refrigerado com melhor padrão de qualidade.

\section{CONCLUSÕES}

As propriedades rurais caprinas na região de Macaíba/RN apresentam problemas de qualidade higiênico-sanitárias e pontos de contaminação que podem afetar a qualidade do leite cru e dos produtos derivados, demonstrando a ineficiência na execução das Boas Práticas de Ordenha e falha de higienização dos utensílios, dos tetos dos animais e das mãos dos ordenhadores. Portanto, há necessidade dos produtores receberem orientações técnicas e capacitação profissional para aderirem a um sistema de manejo adequado com a correta adoção das boas práticas na ordenha, consequentemente ocorrendo a melhoria da qualidade microbiológica do leite caprino cru refrigerado, atendendo o que preconiza a legislação vigente.

\section{REFERÊNCIAS}

ABREU, E. S. et al. Análise microbiológica de mãos de manipuladores de alimentos do município de Santo André. Revista Univap, v. 17 , n. $30,2011$.

AMARAL, D. S. et al. Tendências de consumo de leite de cabra: enfoque para a melhoria da qualidade. Revista Verde, v. 6, n. 1, p. 39-42, 2011.

ANDRADE, A. P. C. et al. Perfil de Staphylococcus coagulase positiva e negativa contaminantes de queijo de coalho. Boletim de Pesquisa e Desenvolvimento. Embrapa Agroindústria Tropical, Fortaleza, CE, p. 9, 2011.

BELMONT, A. R. B. Avaliação das condições físicas e sanitárias das fazendas de produção de leite caprino na região de Macaíba-RN. 2013. 70 f. Monografia (Graduação em Zootecnia) - Universidade Federal do Rio Grande do Norte, Natal, 2013. 
BRASIL. Ministério da Agricultura, Pecuária e Abastecimento. Regulamento Técnico de Identidade e Qualidade de Leite de Cabra. Instrução Normativa $n^{0} 37$ de 31 de outubro de 2000. Departamento de Inspeção de Produtos de Origem Animal. Diário Oficial da República Federativa do Brasil. Brasília, DF, nov. 2000.

BRASIL. Ministério da Agricultura, Pecuária e Abastecimento. Departamento de Inspeção de Produtos de Origem Animal. Instrução Normativa $n^{\circ} 62$, de 26 de agosto de 2003. Oficializa os métodos analíticos oficiais para análises microbiológicas para controle de produtos de origem animal e água. Diário Oficial da República Federativa do Brasil, Brasília, 18 set. 2003 . Seção 1, p. 14.

CARDOSO, M. C. C. et al. Sistema de produção e comercialização do leite de cabra produzido no município de Currais Novos/ RN. Holos, v. 1, p. 31-40, 2010.

CASTRO, K. A. et al. Efeito da contagem de células somáticas sobre a qualidade dos queijos prato e mussarela. Revista Brasileira de Tecnologia Agroindustrial, v. 8, n. 1, p. 1237-1250, 2014.

CAVAlCANTE, M. P. et al. Bactérias envolvidas nas mastites subclínicas de cabra da região de Salvador, Bahia. Arquivo Instituto Biológico, v. 80, n. 1, p. 19-26, 2013.

IBGE - Instituto Brasileiro de Geografia e Estatística. Cidades, 2013. Diretoria de Pesquisas, Coordenação de Agropecuária, Pesquisa da Pecuária Municipal 2013. v. 41, 2013. Disponível em < www.ibge.gov.br $>$. Acesso em: 28 jun. 2016.

KOCHANSKI, S. et al. Avaliação das condições microbiológicas de uma unidade de alimentação e nutrição. Alimentos e Nutrição, v. 20, n. 4, p. 663-668, 2009.
MATSUBARA M. T. et al. Boas práticas de ordenha para redução da contaminação microbiológica do leite no agreste Pernambucano. Semina: Ciências Agrárias, v. 32, n. 1, p. 277-286, 2011.

MONTES, D. F. M. et al. Indicadores de qualidade microbiológica do leite caprino produzido na Paraíba. Agropecuária Científica no Semiárido, v. 12, n. 4, p. 354-358, 2016.

RIBEIRO JR, J. C. R. et al. Influência de boas práticas de higiene de ordenha na qualidade microbiológica do leite cru refrigerado. Revista do Instituto de Laticínios Cândido Tostes, v. 69, n. 6, p. 395-404, 2014.

SALVADOR, F. C. et al. Avaliação da qualidade microbiológica do leite pasteurizado comercializado em Apucarana-PR e região. Revista F@pciência, v. 9, n. 5, p. 30-41, 2012.

SANTANA, E. H. W. Estafilococos em alimentos. Arquivo do Instituto Biológico, v. 77 , n. 3, p. 545-554, 2010.

SILVA, N. et al. Manual de Métodos de Análise Microbiológica de Alimentos e água. $4^{\mathrm{a}}$ ed. São Paulo: Livraria Varela, 2010. 624 p.

SILVA, J. N. et al. Parâmetros e determinantes da qualidade físico-química do leite caprino: revisão de literatura. Revista Verde, v. 6, n. 3, p. 32-38, 2011.

SOUZA, F. M.; NOGUEIRA, M. S.; NUNES, F. C. Qualidade microbiológica do leite cru comercializado informalmente na cidade de Areia-PB. Agropecuária Técnica, v. 32, n. 1, p 168-171, 2011.

ZENI, M. P. et al. Influência dos microrganismos psicrotróficos sobre a qualidade do leite refrigerado para produção de UHT. Unoesc \& Ciência, v. 4, n. 1, p. 61-70, 2013. 